\title{
Electrical stimulation enhances tissue reorganization during orthodontic tooth movement in rats
}

\author{
Gisele Sampaio Spadari ${ }^{1}$ Ewerton Zaniboni ${ }^{2}$ - Silvia Amelia Scudeler Vedovello ${ }^{1}$. \\ Mauro Pedrine Santamaria ${ }^{4}$ - Maria Esméria Corezola do Amaral $^{3}$. \\ Gláucia Maria Tech dos Santos ${ }^{3}$ - Marcelo Augusto Marretto Esquisatto ${ }^{3}$. \\ Fernanda Aparecida Sampaio Mendonca ${ }^{3}$ • Milton Santamaria-Jr ${ }^{1,3}$
}

Received: 16 June 2015 / Accepted: 19 February 2016/Published online: 26 February 2016

(C) Springer-Verlag Berlin Heidelberg 2016

\begin{abstract}
Objective This study evaluated the effects of a low-intensity electric current on tissue reorganization during experimental orthodontic tooth movement.

Materials and methods Thirty-two animals were divided into two groups evaluated on days 3 and 7: OTM-orthodontic tooth movement and OTM + MC- orthodontic tooth movement and microcurrent application $(10 \mu \mathrm{A} / 5 \mathrm{~min})$. The samples were processed for histological, morphometric, and Western blotting analysis.

Results Analysis of the periodontal ligament (PL) showed a significantly smaller number of granulocytes in the OTM + $\mathrm{MC}$ group on day 7.The number of fibroblasts was significantly higher in the OTM $+\mathrm{MC}$ group on days 3 and 7 . The area of birefringent collagen fibers was more organized in the OTM + MC group on days 3 and 7. The number of blood vessels was significantly higher in the OTM + MC group on day 7 . Microcurrent application significantly increased the number of osteoclasts in the compression region of the PL. In the
\end{abstract}

Milton Santamaria-Jr

santamariajr@mailcity.com

1 Graduate Program of Orthodontics, Heminio Ometto University Center, UNIARARAS, Dr. Maximiliano Baruto, 500, Araras, SP 13607-339, Brazil

2 School of Dentistry, Heminio Ometto University Center, UNIARARAS, Dr. Maximiliano Baruto, 500, Araras, SP 13607-339, Brazil

3 Graduate Program of Biomedical Sciences, Heminio Ometto University Center, UNIARARAS, Dr. Maximiliano Baruto, 500, Araras, SP 13607-339, Brazil

4 Division of Periodontics, College of Dentistry, State University of São Paulo, UNESP, Av. Eng. Francisco José Longo, 777, São José dos Campos, SP 12245-000, Brazil
OTM + MC group on day 7 of tooth movement, the expression of TGF- $\beta 1$ and VEGF was significantly reduced whereas the expression of bFGF was increased in PL.

Conclusions Electrical stimulation enhances tissue responses, reducing the number of granulocytes and increasing the number of fibroblasts, blood vessels, and osteoclasts and modulates the expression of TGF- $\beta 1$, VEFG, and bFGF.

Clinical relevance This technique is used in many areas of medicine, but poorly explored in dentistry and orthodontics. This treatment is cheap and non-invasive and can be applied by own orthodontist, and it can improve the treatment with a faster and safe tooth movement, without pain.

Keywords Microcurrent application · Low-intensity electric current $\cdot$ Orthodontic tooth movement

\section{Introduction}

Orthodontic tooth movement causes resorption of alveolar bone on the compression side and osteogenesis on the tension side. Studies investigating the mechanisms involved in this process are important to improve orthodontic treatment [1].

The physical and biological effects of orthodontic tooth movement can be observed early, affecting the extracellular matrix, cells of the alveolar bone, and periodontal ligament (PDL) such as granulocytes, fibroblasts, osteoclasts, and osteoblasts. Furthermore, changes occur in the synthesis and release of cytokines, growth factors, and chemotactic factors [2-4].

The inflammatory responses observed at the beginning of application of an orthodontic force are related to the release of proinflammatory cytokines that affect bone remodeling through the recruitment of osteoclast precursors; in addition, these molecules promote the maturation and activation of 
osteoclasts [5]. An important proinflammatory cytokine is transforming growth factor beta 1 (TGF- $\beta 1$ ), which is abundantly present in the bone matrix [6] and is normally found in periodontal tissue where it plays a key role in tissue remodeling. The expression of TGF- $\beta 1$ is increased during orthodontic tooth movement and this cytokine actively participates in alveolar bone remodeling $[1,7]$.

Similarly, vascular endothelial growth factor (VEGF) is involved in the remodeling of periodontal tissue and alveolar bone, stimulating angiogenesis. During orthodontic tooth movement, VEGF in particular mediates angiogenesis and tissue changes in the PDL $[8,9]$.

Basic fibroblast growth factor (bFGF) is involved in the proliferation of fibroblasts and endothelial cells, angiogenesis, macrophage chemotaxis, and osteoblast and osteoclast differentiation and, consequently, in bone reconstruction [10-13].

The application of electric fields and continuous currents similar to those generated physiologically by the organism can modify cell behavior [14] and induce changes in the skin [15], cartilage [16, 17], tendons [18, 19], and bone [20, 21]. Changes also occur in the transport of ions across cell membranes, as well as in the migration of leukocytes, macrophages, and keratinocytes and in the proliferation of vascular endothelial cells, osteoblasts, osteoclasts, chondrocytes, and fibroblasts [22-24]. In vitro studies have suggested that electrical stimulation affects cellular mechanisms such as ATP production and protein synthesis, exerts antioxidant effects, and promotes changes in blood flow and in transmembrane transport, as well as inducing the synthesis and release of epidermal and vascular growth factors and the expression of their respective receptors [25].

The combination of exogenous electric currents with other therapies has demonstrated beneficial effects in experimental procedures [26-29]. The electric parameters to be used, such as the intensity of the energy applied, amplitude of stimulation, and frequency of application, should be adjusted considering the type of target tissue in order to obtain an adequate biological response, since an increase in intensity and certain frequencies of electric currents can reduce proliferation and induce cell death [30,31]. The local application of exogenous electric currents combined with tooth movements can accelerate orthodontic treatment [32, 33]. In an experimental study, Hashimoto [34] investigated the effects of microcurrent application $(10 \mu \mathrm{A})$ on the tooth surface of cats. The author observed that this treatment increased bone deposition and concluded that microcurrent application combined with a mechanical force may accelerate alveolar bone remodeling and orthodontic tooth movement.

Although the use of low-intensity electric currents has been studied for a long time [21,35-41], their acceptance in clinical practice requires more detailed investigation of other parameters and protocols. Within this context, it is important to establish standard electric parameters of intensity, frequency, and time of application [42] and to investigate their effects on the different cellular and molecular elements that modulate tissue remodeling. Furthermore, the application of a lowintensity electric current has attracted clinical interest since it is a noninvasive therapeutic method that can be used as a coadjuvant in different treatments. Other advantages are that the method is safe, easy to use, simple, and inexpensive [43, 44].

Therefore, the objective of the present study was to investigate tissue reorganization in an experimental model of orthodontic tooth movement in Wistar rats using a new protocol of low-intensity electric current application. The hypothesis was that this therapy contributes to the efficacy of orthodontic treatment.

\section{Materials and methods}

\section{Animals}

Thirty-two male Wistar rats (Rattus norvegicus), 90 days old and weighing on average $300 \mathrm{~g}$, were obtained from the Animal Experimentation Center of Herminio Ometto University Center, UNIARARAS. The animals were housed in individual polycarbonate cages at a constant temperature $\left(23 \pm 2{ }^{\circ} \mathrm{C}\right)$ and humidity $(55 \%)$ under a 12-h light/dark cycle with food and water ad libitum.

The animals were randomly divided into two groups of 16 animals each: one group submitted only to orthodontic tooth movement (OTM) and another group submitted to orthodontic tooth movement combined with microcurrent application $(\mathrm{OTM}+\mathrm{MC})$.

All procedures performed in the present research were in accordance with the ethical standards of the Research Ethics Committee of Herminio Ometto University Center (permit no. 095/2011) and with the 1964 Helsinki Declaration and its later amendments or comparable ethical standards.

\section{Orthodontic tooth movement}

For installation of the tooth movement device, the animals received general anesthesia consisting of the intraperitoneal administration of xylazine hydrochloride $(0.2 \mathrm{mg} / \mathrm{kg})$ and $\mathrm{ke}-$ tamine hydrochloride $(1 \mathrm{ml} / \mathrm{kg})$.

A stainless steel closed coil spring was installed between the left upper first molar (force site) and the upper incisors (anchorage site) according to Heller and Nanda [45], which permitted tip forward movement of the first molar (Fig. 1a). The coil spring was stretched from 4 to $6 \mathrm{~mm}$, releasing a 0.4 $\mathrm{N}$ initial force [46]. 


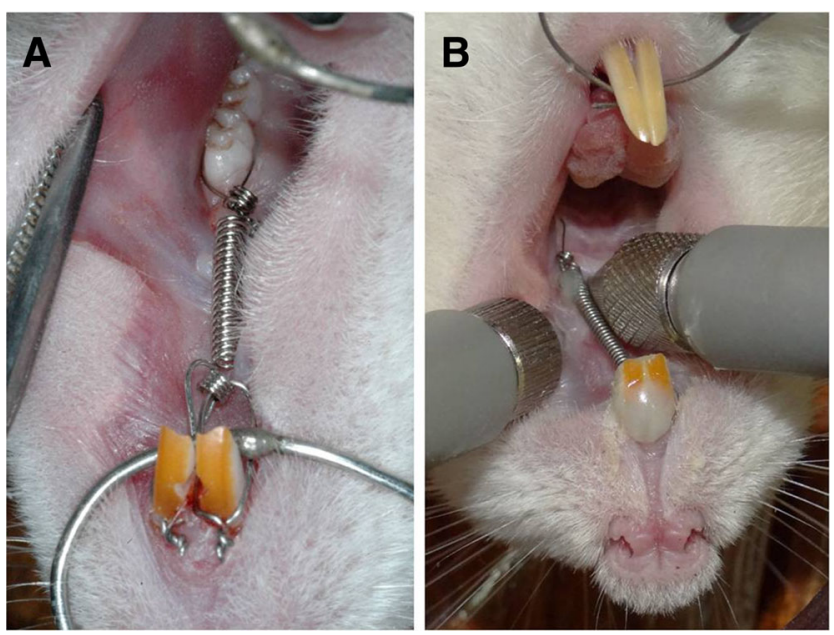

Fig. 1 Stainless steel spring attached to induced tooth movement (a) and the application of electrical current stimulation $(10 \mu \mathrm{A} / 5 \mathrm{~min})$ (b) during the experimental days 3 and 7

\section{Microcurrent application}

A transcutaneous electric stimulator (Physiotonus Microcurrent, BIOSET®, Rio Claro, Sao Paulo, Brazil) was used for microgalvanic stimulation (continuous current of $10 \mu \mathrm{A})$ [21]. For daily application, two metal electrodes with metallic spherical ends were placed in the mesiobuccal and mesiopalatal region of the first molar applied for $5 \mathrm{~min}$ $(10 \mu \mathrm{A} / 5 \mathrm{~min})$ (Fig. 1b). The device was calibrated by the manufacturer.

\section{Structural and morphometric analysis}

Samples ( $n=5$ per experimental period) were collected on days 3 and 7 of tooth movement after anesthesia and cervical dislocation. The epithelial and muscular components surrounding the maxilla were removed and fixed in $10 \%$ form-

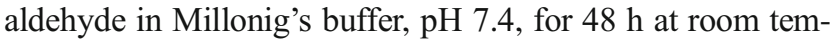
perature. The tissue samples were then demineralized in EDTA-containing decalcifying solution for approximately 2 months. After this period, the specimens were washed in buffer and submitted to standard procedures for embedding in Paraplast ${ }^{\mathrm{TM}}$ (Histosec ${ }^{\circledR}$, Merck). Transversal cross sections $(6 \mu \mathrm{m})$ were cut from the specimens to permit visualization of all roots of the left upper first molar until the cervical region of the periodontal tissue and roots were reached. The distobuccal root was used to identify the PDL areas undergoing tension and compression. In the tension region, the number of fibroblasts and blood vessels $\left(n / 10^{4} \mu \mathrm{m}^{2}\right)$ was determined by staining with toluidine blue in McIlvaine's buffer, $\mathrm{pH} 4.0$; granulocytes were counted $\left(n / 10^{4} \mu \mathrm{m}^{2}\right)$ using the method of Dominici [47]. In the compression region, the total number of osteoclasts $\left(n / 10^{4} \mu \mathrm{m}^{2}\right)$ in alveolar bone superface was determined by toluidine blue staining. Three samplings of $10^{4} \mu^{2}$ were performed for each of the five sections obtained per animal in each group.

Using sections stained by the picrosirius-hematoxylin method [48], the mesiobuccal root was analyzed to quantify the content of birefringent collagen fibers ( $\%$ of total area) in the tension region. Birefringence is an indicator of the caliber and organization of collagen fibers in tissue. For measurement of the area of birefringent fibers, the images captured were analyzed with a Leica DM2000 photomicroscope under polarized light.

All measurements were made on images obtained from the original image documented with a $40 \times$ objective using the Sigma Scan Pro $5.0^{\mathrm{TM}}$ program. The data were analyzed by the Student's $t$ test using spreadsheets of the Excel for Windows XPTM software.

\section{Western blotting}

The periodontal tissue (alveolar bone + PDL) of the moved molar of the different groups ( $n=3$ ) was curetted. For protein extraction, the samples were homogenized in a Polytron PTA 20S homogenizer (model PT 10/35; Brinkmann Instruments, Westbury, NY, USA) operating at maximum speed for $40 \mathrm{~s}$ in buffer (10 mM EDTA, $100 \mathrm{mM}$ Tris base, $10 \mathrm{mM}$ sodium pyrophosphate, $100 \mathrm{mM}$ sodium fluoride, $100 \mathrm{mM}$ sodium orthovanadate, $2 \mathrm{mM}$ PMSF, $0.1 \mathrm{mg} / \mathrm{mL}$ aprotinin in $25 \mathrm{~mL}$ deionized water; Sigma Chemical Co., St. Louis, MO, USA). Next, $10 \%$ Triton X-100 (10\% of the volume used per sample) was added. After $40 \mathrm{~min}$, the mixture was centrifuged at $12,000 \mathrm{rpm}$ for $40 \mathrm{~min}$ at $4{ }^{\circ} \mathrm{C}$ for removal of insoluble material. The supernatant was collected for the measurement of protein concentrations in the samples by the biuret method [49] (Protal colorimetric method, Laborlab, São Paulo, Brazil).

Aliquots of the supernatant were treated with Laemmli buffer containing $100 \mathrm{mM}$ DTT (Sigma Chemical Co.). Samples containing $50 \mu \mathrm{g}$ protein were boiled for $5 \mathrm{~min}$ and submitted to sodium dodecyl sulfate-polyacrylamide gel electrophoresis (SDS-PAGE) on $10 \%$ (VEGF, $40 \mathrm{kDa}$ ) and $12 \%$ gels (TGF $\beta 1$ and FGF-2, 25, and $24 \mathrm{kDa}$, respectively) in a mini-gel apparatus (Mini-Protean ${ }^{\circledR}$, Bio-Rad, Richmond, CA, USA). The proteins were then transferred from the gel to a nitrocellulose membrane (Hybond ECL, $0.45 \mu \mathrm{m}$ ). The membranes were washed in basal solution (1 M Tris base, $5 \mathrm{M}$ $\mathrm{NaCl}, 0.005 \%$ Tween 20, and deionized water for $2 \mathrm{~L}$ ) and incubated in blocking solution (basal solution in $5 \%$ skimmed milk power, Molico ${ }^{\circledR}$ ) for $2 \mathrm{~h}$. After washing in basal solution, the membranes were incubated overnight at $4{ }^{\circ} \mathrm{C}$ with specific antibodies against the different proteins diluted 1:200 (antiTGF- $\beta 1$, anti-FGF-2, and anti-VEGF; Santa Cruz Biotechnology, USA) and against $\beta$-actin diluted 1:1000 (Cell Signaling Technology). Next, the membranes were incubated with the specific secondary antibodies (IgG1:HRP, 
1:1000; Santa Cruz Biotechnology) for $2 \mathrm{~h}$ at room temperature. The reactions were developed with a chemiluminescent kit (SuperSignal ${ }^{\circledR}$ West Pico Chemiluminescent Substrate 34080, Thermo Scientific, USA) for $2 \mathrm{~min}$, and the membranes were photodocumented with the Syngene G:BOX system. Band intensity was evaluated by densitometry using the Scion Image 4.0.3.2 software (Scion Co., USA). Statistical analysis was performed by the Student's $t$ test $(p<0.05)$ using spreadsheets of the Excel for Windows XPTM program.

\section{Results}

\section{Structural and morphometric analysis}

Figures 2 and 3 show the histological alterations that occurred in the PDL of the distobuccal and mesiobuccal roots of the left upper first molar, respectively, after orthodontic force application alone and combined with microcurrent stimulation. Application of an orthodontic force promotes PDL stretching on the distal side of periodontal tissue, while it exerts compression on the mesial side.

Analysis of the distobuccal root of samples of the OTM group on day 3 showed a regular alveolar bone surface on the tension side and an irregular surface on the compression side, probably indicating the beginning of bone remodeling. The periodontal space was smaller on the compression than on the tension side. In some samples, the root surface in the compression region was irregular, indicating the resorption of cementum. On the other hand, no root resorption was observed on the tension side. On day 7 of orthodontic tooth movement, bone resorption lacunae were more evident on the surface of the alveolar bone in the compression region.

Comparison of samples obtained from the OTM + MC and OTM groups revealed no important structural differences at either experimental period studied.

In morphometric analysis (Fig. 4), the number of granulocytes in the tension side of the distobuccal root PDL was significantly higher in samples of the OTM + MC group on day $3(\mathrm{OTM}$, mean $18 \pm 3$; OTM + MC, mean $25 \pm 4)$ and decreased significantly on day 7 when compared to the OTM group (OTM, mean $28 \pm 5$; OTM + MC, mean $12 \pm 4$ ).

The number of fibroblasts in the tension region of the PDL of the distobuccal root was significantly higher in animals of the OTM + MC group on days $3(\mathrm{OTM}=26 \pm 5$, OTM + $\mathrm{MC}=35 \pm 4)$ and $7(\mathrm{OTM}=30 \pm 4.5, \mathrm{OTM}+\mathrm{MC}=42 \pm 5)$ compared to that in the OTM group.

The area occupied by birefringent collagen fibers in the tension region of the PDL of the mesiobuccal root was similar in the two groups on days $3($ OTM $=20.5 \pm 4$; OTM + $\mathrm{MC}=23.5 \pm 4.5)$ and $7(\mathrm{OTM}=22 \pm 3.5$, OTM + $\mathrm{MC}=24 \pm 5$ ).

The number of newly formed vessels in the tension region of the PDL of the distobuccal root did not differ between groups on day $3(\mathrm{OTM}=4.5 \pm 0.8, \mathrm{OTM}+\mathrm{MC}=5 \pm 0.9)$, while higher values were observed in the OTM $+\mathrm{MC}$ group on day $7(\mathrm{OTM}=5 \pm 0.7$, OTM $+\mathrm{MC}=7 \pm 0.6)$.

Analysis of the compression region of the PDL of the intermediate vestibular root showed a significantly larger number of osteoclasts in the OTM + MC group on days 3
Fig. 2 Cross sections of the distobuccal root of the upper first molar of male rats at 3 and 7 days of induced tooth movement. OTM animals submitted only to orthodontic tooth movement, $O T M+M C$ animals submitted to orthodontic tooth movement and microcurrent application, $F$ force direction (red arrow), $P$ pulp, $D$ dentin, $C$ cementum, $P D L$ periodontal ligament. The sections were stained with toluidine blue and analyzed under bright-field illumination. Asterisk: alveolar bone, arrow: blood vessels, arrowhead: fibroblasts. Bar $=200 \mu \mathrm{m}$
$3 d$

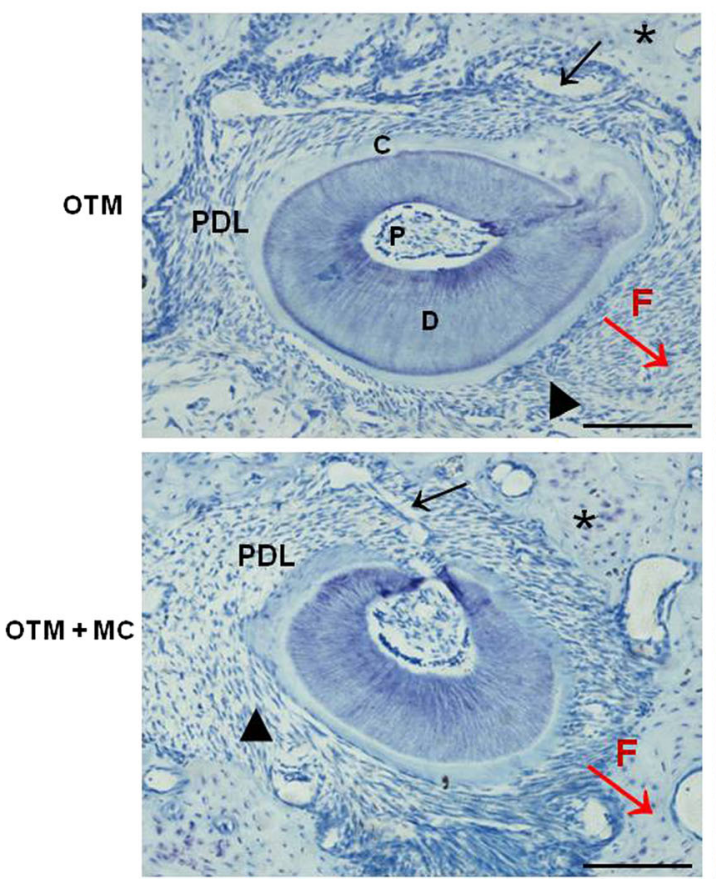

$7 d$
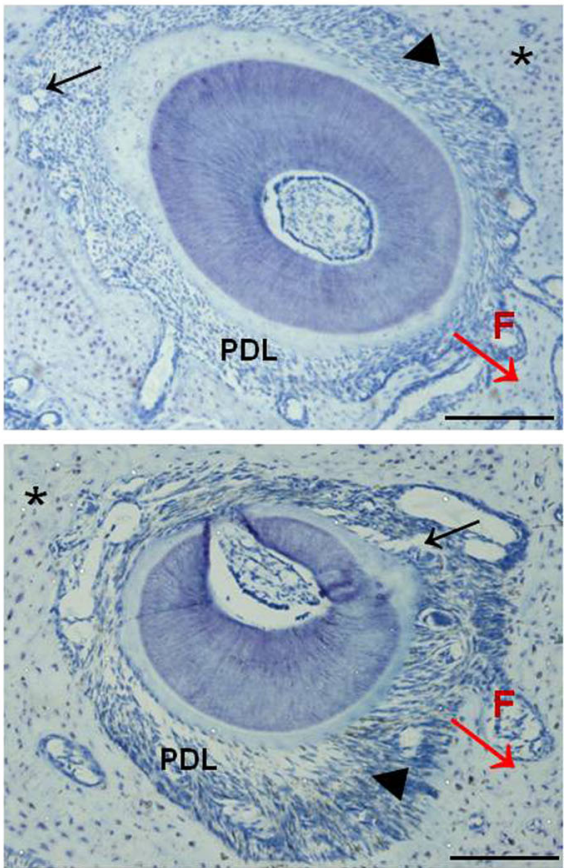
Fig. 3 Cross sections of the mesiobuccal root of the upper first molar of male rats at 3 and 7 days of induced tooth movement. OTM animals submitted only to orthodontic tooth movement, $O T M+M C$ animals submitted to orthodontic tooth movement and microcurrent application, $F$ force direction (red arrow), $P$ pulp, $D$ dentin, $C$ cementum, $P D L$ periodontal ligament. The sections were stained with picrosirius-hematoxylin and analyzed under bright-field illumination and polarized light (pol). Asterisk: alveolar bone, arrowhead: collagen fibers of the PDL. Bar $=200 \mu \mathrm{m}$

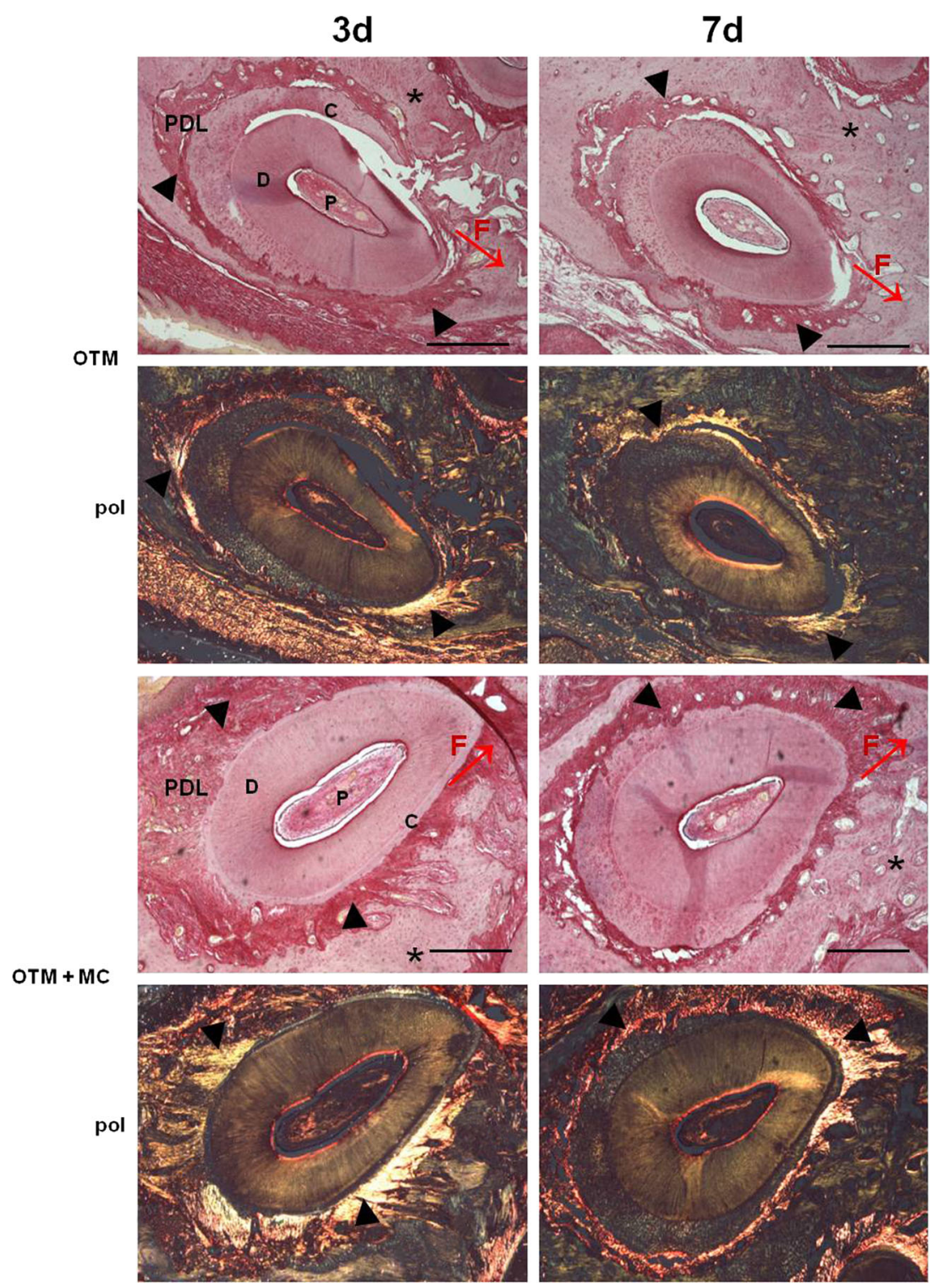

$(\mathrm{OTM}=3 \pm 0.5, \mathrm{OTM}+\mathrm{MC}=4 \pm 0.45)$ and 7 $(\mathrm{OTM}=5 \pm 0.4, \mathrm{OTM}+\mathrm{MC}=6 \pm 0.3)$.

\section{Analysis of cytokines by Western blotting}

Analysis of densitometry and the expression of TGF- $\beta 1$, VEGF, and bFGF (Fig. 5) by Western blotting showed differences in the level of these cytokines in the two groups (OTM and OTM + MC). Densitometric analysis of TGF- $\beta 1$ ( OTM = $221 \pm 50$, OTM + $\mathrm{MC}=248 \pm 50)$ and VEGF $(\mathrm{OTM}=199 \pm 63$, OTM $+\mathrm{MC}=238 \pm 52$ ) revealed no differences in the expression of these cytokines in the two groups on day 3 . However, a significant reduction in the expression of these cytokines TGF- $\beta 1(\mathrm{OTM}=233 \pm 50$, OTM + $\mathrm{MC}=134 \pm 13)$ and $\operatorname{VEGF}(\mathrm{OTM}=268 \pm 9$, OTM $+\mathrm{MC}=116 \pm 32$ ) was observed on day 7 in animals treated with a microcurrent. The expression of bFGF was similar in the two groups on day 3 $(\mathrm{OTM}=59 \pm 9, \mathrm{OTM}+\mathrm{MC}=62 \pm 5)$, but an increase was observed on day $7($ OTM $=47 \pm 14$, OTM + $\mathrm{MC}=79 \pm 8$ ) in animals treated with a microcurrent.

\section{Discussion}

Inflammatory responses in periodontal connective tissues are observed at the beginning of application of these forces and are the result of the release of different proinflammatory cytokines that act as chemotactic factors for neutrophils and macrophages and play an important role in mineralized tissues, inducing local osteoclastic effects $[50,51]$. The role of cytokines in orthodontic tooth movement has been 


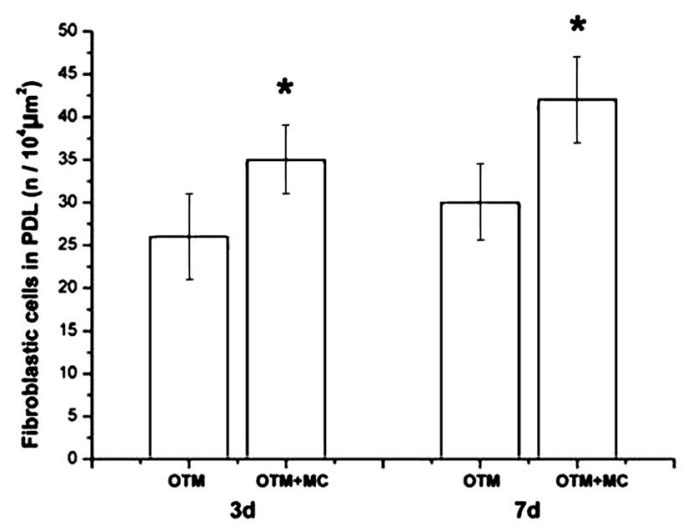

A

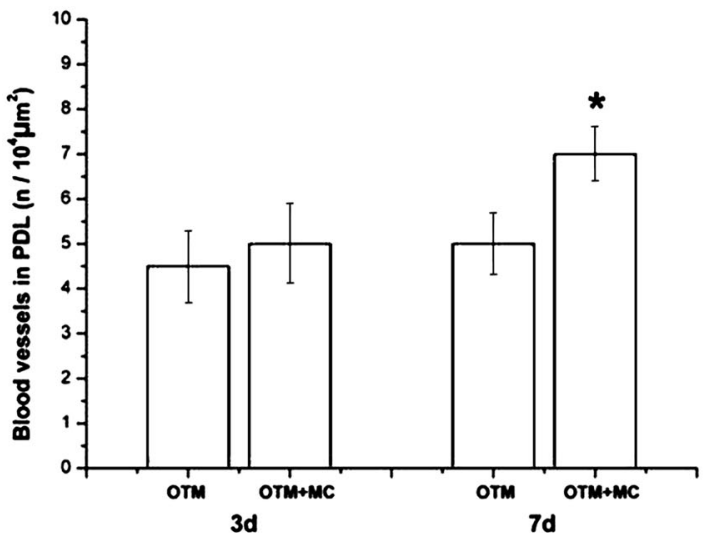

C

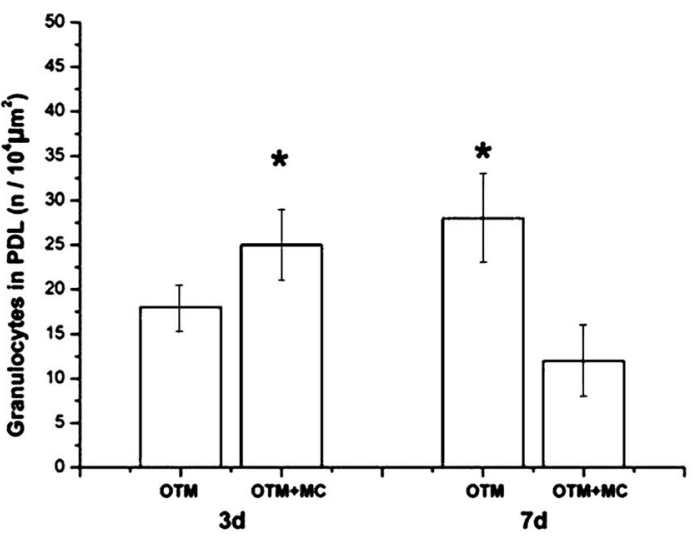

B

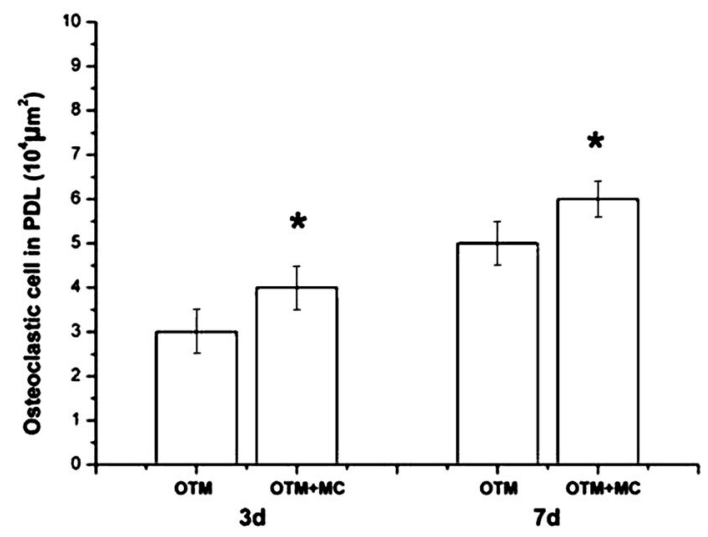

D

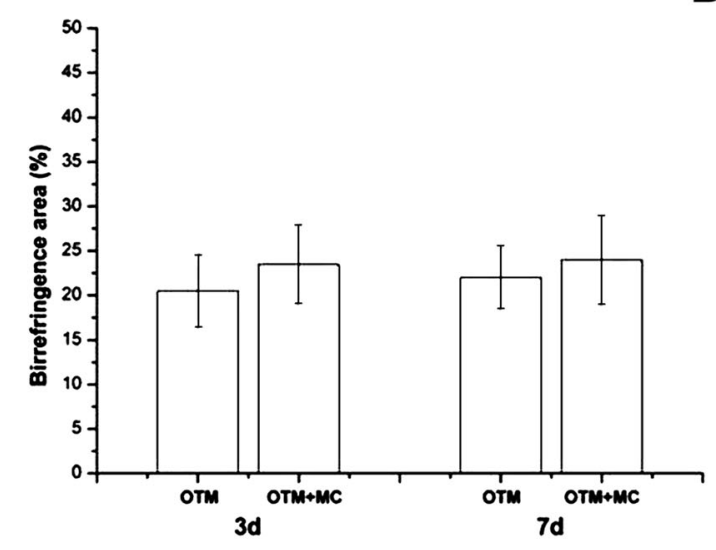

$\mathbf{E}$

Fig. 4 Total number of fibroblasts (a), granulocytes (b), newly formed blood vessels (c), osteoclasts (d), and the birefringence area of collagen fibers (e) in the periodontal ligament (PDL) of roots from maxillary first molar of the male rats after $3(3 d)$ and $7(7 d)$ days of orthodontic tooth movement $(O T M)$. Experimental groups: OTM without additional

investigated $[2,9]$, and studies suggest that the stimulation of inflammatory cytokine expression increases bone remodeling, favoring orthodontic tooth movement. Furthermore, these molecules recruit osteoclast treatment, $O T M+M C$ treatment with microcurrent $(10 \mu \mathrm{A} / 5 \mathrm{~min} /$ day $)$. The results are reported as the mean and standard deviation of each group and were compared by Student's $t$ test $(p<0.05)$. *Significant intergroup difference

precursors from the circulation and promote the maturation and activation of these cells [5].

The TGF- $\beta 1$ is a cytokine that plays a crucial role in the regeneration of connective tissue and bone remodeling, with 
IB: TGF

IB: b-actin

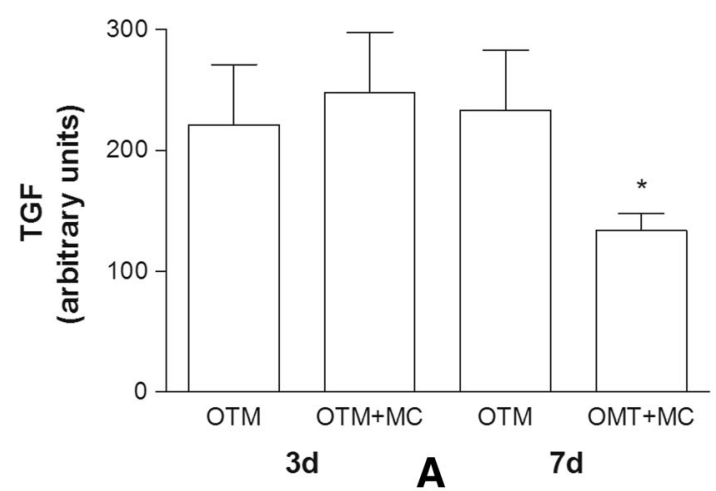

IB: VEGF

IB: b-actin

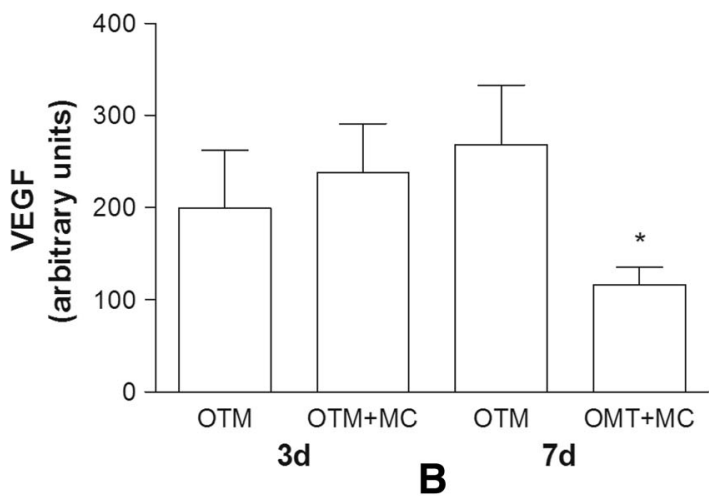

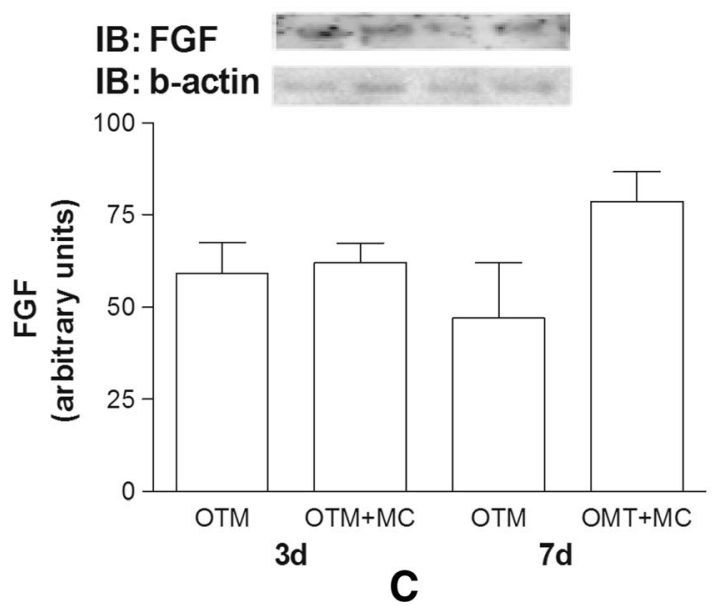

Fig. 5 Analysis of TGF- $\beta 1$ (a), VEGF (b), and bFGF (c) protein expressions in the periodontal ligament and alveolar bone of the upper first molar obtained from male rats at 3 and 7 days of induced tooth movement. OTM animals submitted only to orthodontic tooth movement, $O T M+M C$ animals submitted to orthodontic tooth

significant effects on osteogenic differentiation and bone formation, recruiting leukocytes and inducing the inflammatory phase [52-54].

In the present study, the expression of TGF- $\beta 1$ was slightly increased during the early stage of orthodontic tooth movement (day 3) in animals of the OTM + MC group, while a reduction in this cytokine was observed on day 7 in this group. Morphometric analysis of samples obtained from the tension region of the PDL of the distobuccal root revealed a significant reduction in the number of granulocytes on day 7 in the OTM + MC group when compared to day 3 . These data suggest that microcurrent application may have reduced the development of inflammation during the early stages of tooth movement in this experimental model, favoring bone remodeling. Inflammation is beneficial during tooth movement, but can have destructive effects on the periodontium and tooth structure if it is not controlled [5]. movement and microcurrent application. In the graph, values are expressed as the mean \pm standard deviation. $* p<0.05$ : significant difference compared to OTM (Student's $t$ test). The representative immunoblot $(I B)$ is shown above the graph

With respect to bFGF, higher expression was observed in alveolar bone samples of the moved tooth obtained from animals of the OTM + MC group on day 7 compared to the OTM group. The bFGF is an important growth factor which is involved in angiogenesis and plays a significant role in chemotaxis and mitogenesis of PDL cells, accelerating the regenerative process $[2,12,55]$. Microcurrent application promoted an increase in bFGF at the two experimental periods studied. Thus, our results suggest that this MC treatment protocol may have favored bone remodeling since it appears to induce the proliferation of fibroblasts, as observed in our analysis. Other studies indicate that the FGF also orchestrates angiogenesis [56-58]. Seifi et al. [55] demonstrated the beneficial effects of bFGF injection at the site of tooth movement and concluded that this protocol may reduce the duration of orthodontic treatment.

Fibroblasts are also present in large numbers in the PDL and an increase in the proliferation of these cells favors the 
deposition and organization of collagen fibers in the extracellular matrix. Different studies confirm the increase in fibroblast proliferation in the presence of a mechanical stimulus [1, $59,60]$. In the present study, MC-treated samples exhibited similar results in terms of the increase in bFGF expression and in the number of fibroblasts on the tension side at the two experimental periods studied. The same response was not observed for the percentage of birefringent collagen fibers, indicating that the experimental period may not have been sufficient to modify the dynamics of fiber reorganization in the PDL, as observed in previous studies using other tissues. With respect to these parameters in particular, Campos Ciccione et al. (2013) [16] and Zuzzi et al. (2013) [17] observed positive effects of microcurrent stimulation on the total number of fibroblasts and a consequent increase in birefringent collagen fiber content during the repair of non-articular cartilage in young and adult Wistar rats. A study investigating the bone repair of Wistar rat calvarial defects also showed an increase in fibroblast proliferation in samples submitted to microcurrent application $(10 \mu \mathrm{A} / 5 \mathrm{~min})$ [21].

In the present study, the expression of VEGF was significantly reduced in the OTM + MC group on day 7 when compared to the early stage of orthodontic tooth movement (day 3 ). This result suggests that microcurrent application favored angiogenesis, since the release of VEGF is induced by cells submitted to hypoxia, a characteristic of the early stages of orthodontic tooth movement, and its expression decreases with the reestablishment of tissue oxygenation [61, 62]. Furthermore, morphometric analysis demonstrated a significant increase in the number of blood vessels during this period in the OTM + MC group. Microcurrent stimulation is an important tool for tissue repair since it also promotes the formation of new blood vessels [25]. Mendonça et al. [21], using the same intensity and time of electric stimulation $(10 \mu \mathrm{A} / 5 \mathrm{~min})$, also observed an increase in the number of newly formed vessels during the repair of calvarial bone defects in Wistar rats.

The VEGF is also involved in the differentiation of osteoclasts [63]. According to Di Alberti et al. [64], VEGF participates in tissue repair and bone remodeling in peri-implantitis lesions by regulating the formation and migration of osteoclasts. In the present study, an increase in the number of osteoclasts was observed in samples of the OTM + MC group. This finding indicates that this therapy increased the number of these cells, thus favoring bone remodeling since the early stages of orthodontic tooth movement.

Electrical stimulation has been shown to be effective in inducing osteogenesis $[65,66]$. Its cellular effects promoting tissue repair include the attraction and stimulation of neutrophils, leukocytes, and fibroblasts; synthesis of collagen; and bacteriostatic activity $[41,44]$.

The analysis of the parameters studied permits to conclude that microcurrent application combined with induced tooth movement favored tissue responses, reducing the number of granulocytes and increasing the number of fibroblasts, blood vessels, and osteoclasts. The cytokines and growth factors studied (TGF- $\beta 1$, VEFG, and bFGF), which play an important role in tissue repair, were modulated favorably during orthodontic tooth movement when combined with microcurrent application. Further studies are needed to investigate new protocols for the identification of clinically relevant parameters of electric current applications, since the results obtained with this experimental model support the use of low-intensity electric current as a coadjuvant tool in orthodontic treatment.

\section{Compliance with ethical standards}

Funding This study was funded by the National Council for Scientific and Technological Development - CAPES/PNPD (process no. 23038.008192/2013-01) and Heminio Ometto University Center.

Conflict of interest The authors declare that they have no conflict of interest.

Ethical approval All procedures performed in the present research were in accordance with the ethical standards of the Research Ethics Committee of Herminio Ometto University Center (permit no. 095/ 2011) and with the 1964 Helsinki Declaration and its later amendments or comparable ethical standards.

Informed consent The studied experimental model involves animals (rats), thus informed consent is not necessary.

\section{References}

1. Van Schepdael A, Vander Sloten J, Geris L (2013) A mechanobiological model of orthodontic tooth movement. Biomech Model Mechanobiol 12:249-265

2. Krishnan V, Davidovitch Z (2006) Cellular, molecular, and tissuelevel reactions to orthodontic force. Am J Orthod Dentofacial Orthop 129(469):e1-32

3. Ren Y, Vissink A (2008) Cytokines in crevicular fluid and orthodontic tooth movement. Eur J Oral Sci 116:89-97

4. Krishnan V, Davidovitch Z (2009) On a path to unfolding the biological mechanisms of orthodontic tooth movement. J Dent Res 88: 597-608

5. Teixeira CC, Khoo E, Tran J, Chartres I, Liu Y, Thant LM, Khabensky I, Gart LP, Cisneros G, Alikhani M (2010) Cytokine expression and accelerated tooth movement. J Dent Res 89: $1135-1141$

6. Bismar H, Klöppinger T, Schuster EM, Balbach S, Diel I, Ziegler R, Pfeilschifter J (1999) Transforming growth factor beta (TGF-beta) levels in the conditioned media of human bone cells: relationship to donor age, bone volume, and concentration of TGF-beta in human bone matrix in vivo. Bone 24:565-569

7. Garlet TP, Coelho U, Silva JS, Garlet GP (2007) Cytokine expression pattern in compression and tension sides of the periodontal ligament during orthodontic tooth movement in humans. Eur J Oral Sci 115:355-362 
8. Di Domenico M, D'apuzzo F, Feola A, Cito L, Monsurrò A, Pierantoni GM, Berrino L, De Rosa A, Polimeni A, Perillo L (2012) Cytokines and VEGF induction in orthodontic movement in animal models J Biomed Biotechnol 201689.

9. Salomão MFLS, Reis SRA, Vale VLC, Machado CV, Meyer R, Nascimento ILO (2014) Immunolocalization of FGF-2 and VEGF in rat periodontal ligament during experimental tooth movement. Dental Press J Orthod 19:67-74

10. Derringer KA, Linden RW (2004) Vascular endothelial growth factor, fibroblast growth factor 2, platelet derived growth factor and transforming growth factor beta released in human dental pulp following orthodontic force. Arch Biol Oral 49:631-641

11. Sako E, Hosomichi J (2010) Alteration of bFGF expression with growth and age in rat molar periodontal ligament. Angle Orthod 80: 904-911

12. Feito MJ, Lozano RM, Alcaide M, Ramírez-Santillán C, Arcos D, Vallet-Regí M, Portolés MT (2011) Immobilization and bioactivity evaluation of FGF-1 and FGF-2 on powdered silicon-doped hydroxyapatite and their scaffolds for bone tissue engineering. $\mathrm{J}$ Mater Sci Mater Med 22:405-416

13. Qu D, Li J, Li Y, Gao Y, Zuo Y, Hsu Y, Hu J (2011) Angiogenesis and osteogenesis enhanced by bFGF ex vivo gene therapy for bone tissue engineering in reconstruction of calvarial defects. J Biomed Mater Res 96:543-551

14. Agren MS, Werthen M (2007) The extracellular matrix in wound healing: a closer look at therapeutics for chronic wounds. Int J Low Extrem Wounds 6:82-97

15. Neves LMG, Matheus RL, Santos GMT, Esquisatto MAM, Amaral MEC, Mendonça FAS (2013) Effects of microcurrent application and $670 \mathrm{~nm} \mathrm{InGaP} \mathrm{low-level} \mathrm{laser} \mathrm{irradiation} \mathrm{on} \mathrm{experimental}$ wound healing in healthy and diabetic Wistar rats. Laser Phys 23: 035604

16. Campos Ciccone C, Zuzzi DC, Neves LMG, Mendonça JS, Paulo Pinto Joazeiro PP, Esquisatto MAM (2013) Effects of microcurrent stimulation on Hyaline cartilage repair in immature male rats (Rattus norvegicus) BMC Complement. Altern Med 13:17

17. Zuzzi DC, Ciccone CC, Neves LM, Mendonça JS, Joazeiro PP, Esquisatto MA (2013) Evaluation of the effects of electrical stimulation on cartilage repair in adult male rats. Tissue Cell 45:275-281

18. Fujita M, Hukuda S, Doida Y (1992) The effect of constant direct electrical current on intrinsic healing in the flexor tendon in vitro. An ultrastructural study of differing attitudes in epitenon cells and tenocytes. J Hand Surg [Br] 17:94-98

19. Lin YL, Moolenaar H, van Weeren PR, van de Lest CH (2006) Effect of microcurrent electrical tissue stimulation on equine tenocytes in culture. Am J Vet Res 67:271-276

20. Martin RB, Gutman W (1978) The effect of electric fields on osteoporosis of disease. Calcif Tissue Int 5:23-27

21. Mendonça JS, Neves LMG, Esquisatto MAM, Mendonça FAS, Santos GMT (2013) Comparative study of the application of microcurrent and AsGa $904 \mathrm{~nm}$ laser radiation in the process of repair after calvaria bone excision in rats. Laser Phys 23:035605

22. Chao PH, Roy R, Mauck ML, Liu W, Valhmu WB, Hung CT (2000) Chondrocyte translocation response to direct current electric fields. J Biomech Eng 122:261-267

23. McCaig CD, Rajnicek AM, Song B, Zhao M (2005) Controlling cell behavior electrically:current views and future potential. Physiol Rev 85:943-978

24. Funk RH, Monsees TK (2006) Effects of electromagnetic fields on cells: physiological andtherapeutical approaches and molecular mechanisms of interaction. A review. Cells Tissues Organs 182: 59-78

25. Poltawski L, Tim Watson T (2009) Bioelectricity and microcurrent therapy for tissue healing - a narrative review. Phys Ther Rev 14: 104-114
26. Mendonça FAS, Passarini Junior JR, Esquisatto MA, Mendonça JS, Franchini CC, Santos GM (2009) Effects of the application of Aloe vera (L.) and microcurrent on the healing of wounds surgically induced in Wistar rats. Acta Cir Bras 24:150-155

27. De Gaspi FOG, Foglio MA, Carvalho JE, Santos GMT, Testa M, Passarini JR Jr, Moraes CP, Esquisatto MAM, Mendonça JS, Mendonça FAS (2011) Effects of the topical application of hydroalcoholicleaf extract of Oncidium flexuosum Sims. (Orchidaceae) and microcurrent on the healing of wounds surgically induced in Wistar rats. Evid Based Complement Alternat Med:1-9

28. Migliato KF, Chiosini MA, Mendonça FAS, Esquisatto MAM, Salgado HR, Santos GMT (2011) Effect of glycolic extract of Dillenia indica L combined with microcurrent stimulation on experimental lesions in Wistar rats. Wounds 23:111-120

29. Castro FCB, Magre A, Cherpinski R, Zelante PM, Neves LMG, Esquisatto MAM, Mendonça FAZ, Santos GMT (2012) Effects of microcurrent application alone or in combination with topical Hypericum perforatum L and Arnica montana L on surgically induced wound healing in Wistar rats. Homeopathy 101:147-153

30. Blumenthal NC, Ricci J, Breger L, Zychlinsky A, Solomon H, Chen GG, Kuznetsov D, Dorfman R (1997) Effects of lowintensity AC and/or DC electromagnetic fields on cell attachment and induction of apoptosis. Bioelectromagnetics 18:264-272

31. Watson T (2002) Current concepts in electrotherapy. Haemophilia 8:413-418

32. Davidovitch Z, Finkelson MD, Steigman S, Shanfeld JL, Montgomery PC, Korostoff E (1980) Electric currents, bone remodeling, and orthodontic tooth movement increase in rate of tooth movement and periodontal cyclic nucleotide levels by combined force and electric current. Am J Orthod 77:33-47

33. Kim DH, Park YG, Kang SG (2008) The effects of electrical current from a micro-electrical device on tooth movement. Korean J Orthod 38:337-346

34. Hashimoto H (1990) Effect of micro-pulsed electricity on experimental tooth movement. Nihon Kyosei Shika Gakkai Zasshi 49: 352-361

35. Cheng N, Van Hoof H, Bockx E, Hoogmartens MJ, Mulier JC, De Dijcker FJ, Sansen WM, De Loecker W (1982) The effects of electrical currents on ATP generation, protein synthesis, and membrane transport in rat skin. Clin Orthop Relat Res 171:264-272

36. Becker R (1985) The body electric. Willian Morrow and Co, Inc., New York

37. Basset CA (1993) Beneficial-effects of electromagnetic-fields. J Cell Biochem 51:387-393

38. Cheng K, Goldman RJ (1998) Electric fields and proliferation in a dermal wound model: cell cycle kinetics. Bioelectromagnetics 19: 68-74

39. Kloth LC (2005) Electrical stimulation for wound healing: a review of evidence from in vitro studies, animal experiment, and clinical trials. Int J Low Extrem Wounds 4:23-44

40. Mendonça FAS, Santos MTS, Esquissato MAM, Passos LE, Alves AA, Mendonça JS (2005) Efeito da aplicação da microcorrente após fratura. RGO 53:193-197

41. Lee HII, Kim MY, Kwon DR (2009) Therapeutic effect of microcurrent therapy in infants with congenital muscular torticollis. Am J Phys Med Rehabil 1:736-739

42. Balakatounis KC, Angoules AG (2008) Low-intensity electrical stimulation in wound healing: review of the efficacy of externally applied currents resembling the current of injury. Eplasty 16:8-28

43. Thakral G, Lafontaine J, Najafi B, Talal TK, Kim P, Lavery LA (2013) Electrical stimulation to accelerate wound healing. Diabet Foot Ankle 16:1-9

44. Lee BY, Wendell K, AL-Waili N, Butler G (2007) Ultra-low microcurrent therapy: a novel approach for treatment of chronic resistant wounds. Adv Ther 24:1202-1209 
45. Heller IJ, Nanda R (1979) Effect of metabolic alteration of periodontal fibers on tooth movement: an experimental study. Am J Orthod Dentofac Orthop 75:239-258

46. Santamaria M Jr, Milagres D, Stuani AS, Stuani MBS, Ruellas ACO (2006) Initial changes in pulpal microvasculature during orthodontic tooth movement: a stereological study. Eur J Orthod 28: 217-220

47. Dominici M (1902) Sur une methode de technique histologique appropriee a l'etude du systeme hematopoietique. Compt Rend Soc de Biol 54:221-223

48. Junqueira LCU, Bignolas G, Brentani RR (1979) Picrosirius staining plus polarization microscopy, a specific method for collagen detection in tissue sections. Histochem J 11:447-455

49. Gornall AG, Bardawill CJ, David MM (1949) Determination of serum proteins by means of the Biuret reaction. J Biol Chem 177: 751-766

50. Lara VS, Figueiredo F, Silva TA, Cunha FQ (2003) Dentin-induced in vivo inflammatory response and in vitro activation of murine macrophages. J Dent Res 82:460-465

51. Fracalossi AC, Santamaria M Jr, Consolaro MFMO, Consolaro A (2009) Experimental tooth movement in murines: study period and direction of microscopic sections. Rev Dent Press Ortod Ortop Facial 14:143-157

52. Janssens K, Dijke PT, Janssens S, Hul WV (2005) Transforming growth factor-b1 to the bone. Endocr Rev 26:743-774

53. Ripamonti U, Ferretti C, Teare J, Blann L (2009) Transforming growth factor-b isoforms and the induction of bone formation. $\mathrm{J}$ Craniofac Surg 20:1544-1555

54. Zhao L, Jiang S, Hantash BM (2010) Transforming growth factor beta1 induces osteogenic differentiation of murine bone marrow stromal cells. Tissue Eng Part A 16:725-733

55. Seifi M, Badiee MR, Abdolazimi Z, Amdjadi P (2013) Effect of basic fibroblast growth factor on orthodontic tooth movement in rats. Cell J 15:230-237
56. Murakami M, Simons M (2008) Fibroblast growth factor regulation of neovascularization. Curr Opin Hematol 15:215-220

57. Wong VW, Crawford JD. Vasculogenic Cytokines in Wound Healing. Biomed Res Int 2013:190486

58. Asadi MR, Torkaman G, Hedayati M, Mofid M (2013) Role of sensory and motor intensity of electrical stimulation on fibroblastic growth factor-2 expression, inflammation, vascularization, and mechanical strength of full-thickness wounds. J Rehabil Res Dev 50: 489-498

59. Dahl J, Li J, Bring DK, Renström P, Ackermann PW (2007) Intermittent pneumatic compression enhances neurovascular ingrowth and tissue proliferation during connective tissue healing: a study in the rat. J Orthop Res 25:1185-1192

60. Wise GE, King GJ (2008) Mechanisms of tooth eruption and orthodontic tooth movement. J Dent Res 87:414-434

61. Bates DO (2008) Vascular endothelial growth factors and vascular permeability. Cardiovasc Res 87(2):262-271

62. Bao P, Kodra A, Tomic-Canic M, Golinko MS, Ehrlich HP, Brem H (2009) The role of vascular endothelial growth factor in wound healing. J Surg Res 153:347-358

63. Aldridge SE, Lennard TW, Willims JR, Birch MA (2005) Vascular endothelial growth factor receptors in osteoclast differentiation and function. Biochem Biophys Res Commun 335:793-738

64. Di Alberti L, Rossetto A, Albanese M, D'Agostino A, De Santis D, Bertossi D, Nocini PF. Expression of vascular endothelial growth factor (VEGF) mRNA in healthy bone tissue around implants and in peri-implantitis Minerva Stomatol. 2013;11 [Epub ahead of print]

65. Sousa TD, Del Carlo RJ, Viloria MIV (2001) Electrotherapy on the healing process in the articular surface of rabbits. Cienc Rural 31: $819-824$

66. De Angelis V (1970) Observation on the response of alveolar bone to orthodontic force. Am J Orthod 58:284-294 